\title{
A proposed framework for efficient and cost-effective terrestrial orchid conservation
}

(Version 4 - April 24, 2020)

Mark Brundrett

School of Biological Sciences the University of Western Australia and The West Australian Herbarium. Email: mark.brundrett@uwa.edu.au, Phone 0409342878.

\begin{abstract}
This paper presents a comprehensive and adaptive framework for orchid conservation programs illustrated with data from published and unpublished case studies. There is a specific focus on West Australian terrestrial orchids, but many of the approaches have universal relevance. Aspects of the framework include (1) setting appropriate objectives, (2) establishing effective collaborations between scientists, volunteers and regulators to fill knowledge and funding gaps, (3) use of survey and demographics data to determine extinction risks and management requirements for species, (4) effective habitat management to overcome threats such as grazing, (5) finding potential new habitats by modelling climate and site data, (6) investigating the effectiveness of pollinators and (7) using seed baiting to detect mycorrhizal fungi. The relative cost and effectiveness of different methods used to propagate orchids for translocation are compared. Methods known to be successful, in order of complexity, include placement of seed in situ, vegetative propagation, symbiotic germination in non-sterile organic matter, symbiotic germination in sterile culture, asymbiotic sterile germination and clonal division in tissue culture. These form a continuum of complexity, cost, time required, faculties needed, as well as the capacity to maintain genetic diversity and produce seedlings preadapted to survive in situ. They all start with seed collection and lead to seed storage, living collections used as tuber banks and seed orchards, as well as translocation for conservation. They could also lead to commercial availability and sustainable ecotourism, both of which are needed to reduce pressure on wild plants. Overall, there has been a strong preference to use relatively complex, expensive and time-consuming methods for orchid conservation, despite evidence that simpler approaches have also been successful. These simpler methods, which include in situ seed placement and non-sterile germination on inorganic substrates, should be trialled in combination with more complex orchid propagation methods as part of an adaptive management framework. It is essential that orchid conservation projects harness the unique biological features of orchids, such as abundant seed production and mycorrhizal fungi which are far more widespread than their hosts. This is necessary to increase the efficiency and coverage of recovery actions for the largest and most threatened plant family.
\end{abstract}

\section{Introduction}

Orchid conservation research and actions are urgently required, as the largest plant family with half its members listed on the IUCN Global Red List of threatened species (Gale et al. 2018). Major threats to orchids in Australia include loss of habitat, altered fire regimes, tourism and recreation, collecting, drought, weeds and grazing (Brundrett 2007, 2016, Wraith \& Pickering 2019). Most of the orchids in WA are geophytes with summer dormancy and occur in areas of mediterranean climate with relatively high rainfall (Brundrett 2014). There currently are 108 orchids of conservation concern in Western Australia (WA), including 41 threatened taxa and 67 priority taxa. The majority of these (106 spp.) occur in the Southwest Floristic Region of WA.

This document primarily aims to inform discussion and help coordinate orchid conservation projects that are planned or underway in WA. It provides a review of methods that have been successfully utilised, or should be considered for use, especially for terrestrial orchids. These methods primarily concern orchid propagation and translocation, but conservation actions that do not meet the definition of translocation are also important for maintenance of existing rare orchid populations, as explained below. This advice is based on my own practical experiences during two decades of orchid conservation, along with a review of published and unpublished scientific data from relevant research trials and conservation actions. The majority of the cited references and case studies used here are from studies of Australia orchids, but most are equally relevant elsewhere. These guidelines primarily concern orchids so have limited relevance to other plants. 


\section{Standard objectives for projects to conserve rare orchids}

1. Rigorously analyse existing data to understand the conservation status and distribution of species.

2. Undertake additional monitoring as required to accurately measure the size of known populations and search for new populations in other suitable habitats.

3. Measure vital statistics such as flowering, seed set, seedling emergence and the impact of threating processes by annual measurements in fixed areas.

4. Develop and implement site management plans to address threats such as grazing, weeds and human impacts to maintain the viability of populations.

5. Revise threat assessments and recommend changes to the protected status of species if required, based on the size and viability of populations relative to threatening processes.

6. Collect seed for ex situ storage and propagation and any required voucher specimens or genetic material without causing substantial impacts to orchids.

7. Undertake taxonomic and genetic studies required to resolve species whose identity is in doubt and provide essential data for seed collection and translocation.

8. Establish collaborations between government agencies, scientists and community group volunteers to undertake conservation works.

9. Compare the efficiency, cost-effectives and time required for different in situ population augmentation and ex situ propagation methods. Select the most suitable methods.

10. Obtain site and orchid specific information required of successful translocation, such as seed baiting to detect compatible fungi and pollinator studies.

11. Develop and approve translocation plans and gain the required permits.

12. Undertake translocations and/or supplemental pollination and/or in situ seeding and monitor subsequent germination, survival and spread of orchids to confirm objectives are met.

13. Revise plans based on outcomes and reimplement them if objectives are not fully achieved using adaptive management.

14. Establish ex situ orchid collections (tuber banks) at multiple locations and make orchids targeted by collectors available for sale to the public.

15. Support and promote sustainable ecotourism based on some of the most beautiful and popular wildflowers on earth.

\section{Effective collaborations and information sharing}

Collaborations between government agencies, such as botanic gardens, and community groups are at the forefront of orchid conservation in Australia and globally (Marshall et al. 2005, Brundrett 2016, Gale et al. 2018). For example, members of the WA Native Orchid Study and Conservation Group (WANOSCG) implement many rare orchid surveys for the West Australian Department of Biodiversity Conservation and Attractions (DBCA). This started as the Wheatbelt Orchid Rescue Project (2007-2011) and continues as the Adopt an Orchid Project (Brundrett 2016, wanoscg.com/adopt-an-orchid-project). Volunteers in community groups also have a major role in propagating orchids for conservation (Marshall et al. 2005, Wright et al. 2006).

\section{Gathering and working with population survey and vital statistics data}

Surveys of rare orchids in known populations should occur periodically to count individuals present and identify threatening processes. They also seek to find new populations in suitable habitats. Data from rare flora surveys can be used to determine the overall conservation status of species (see Figs. 1, 2, Table 1). However, these surveys only estimate population sizes and outcomes are strongly determined by survey effort and, especially for orchids, the level of experience of participants (Brundrett 2016). In particular it can be difficult to identify non-flowering individuals, since leaves of related species often look very similar. There also are many orchids in WA that cannot be reliably identified when they are flowering, due to integrading taxa, species complexes and very similar orchids named as separate species (see 4).

Numerous records from rare orchid surveys are stored in databases, but this data not being analysed effectively to identify species and populations at greatest risk. It has been determined that efforts to conserve rare species in WA are inadequate overall (Office of the Auditor General Western Australia 2017). Similar 
situation occurs in most other countries (Gale et al 2018). Detailed demographic data is required to understand and manage risks for very rare orchids. Very small populations of these orchids are usually linked to declining habitat condition, ageing populations and infrequent reproduction. So far, I have only been able to set up detailed demographic monitoring plots for 9 of the rarest orchids in WA (e.g. Brundrett 2016).

Analysis of accurate and current population size data for all rare WA orchids is required to assess their status. For example, of the 62 recorded Caladenia huegelii populations, 29 lack extant plants (including 15 sites permanently lost to development) and only 3 populations are large enough to be considered sustainable (Fig. 2A). More detailed studies of several of the largest populations of this species have found they have a very low pollination rate (Fig. 2B), as was also observed in an earlier pollination study across the entire range of this species (Phillips et al. 2015). In comparison, Drakaea elastica had more large populations, based on total leaf counts (Fig. 2C). However, most plants of this species did not flower (Fig. 2D) and seed set was very rare. Furthermore, this is a clonal orchid, so the number of individuals (genets) would be much smaller than leaf numbers (groups have up to 30 leaves). It is necessary to use specific population measurement criteria for different orchids based on their life history strategies, but this is not the current practice in WA.

In addition to population surveys, detailed orchid demographics data are required to measure sustainability of orchid populations and to guide conservation actions (Whigham \& Willems 2003, Brundrett 2016). This essential data includes actual population sizes (including dormant plants), plant lifespans, pollination rates and recruitment rates (Fig. 1A, Table 1). Measuring these requires monitoring of orchids in fixed areas such as transects where the same individual orchids can be identified over time. The methodology outlined in Appendix 1 was developed during the Wheatbelt Orchid Rescue Project (Brundrett 2016). Measuring the position of plants allows individual plants to be identified without the need for visible tags (Fig. 3A) and revealed that only a fraction of plants emerged each year in semiarid WA habitats (Table 1, Fig. 1B).

Table 1. Habitat areas, population sizes, emergence frequency and threats to four endangered wheatbelt orchids (Brundrett 2016). No seedlings were observed in any population. Data were from 2007 to 2011.

\begin{tabular}{|c|c|c|c|c|c|c|c|c|c|}
\hline Orchid & 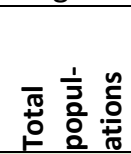 & 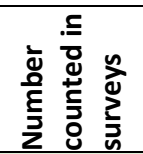 & 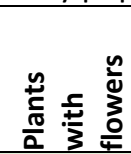 & 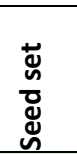 & $\begin{array}{l}\text { D্ } \\
\mathbb{N} \\
\frac{\pi}{0}\end{array}$ & 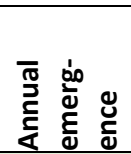 & 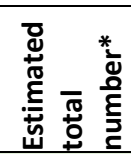 & 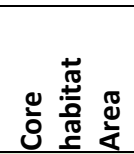 & 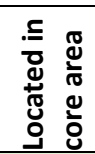 \\
\hline Caladenia williamsiae & $1(2 \#)$ & 450 & $67 \%$ & $15 \%$ & $13 \%$ & $34 \%$ & 1400 & $2 \mathrm{ha}$ & $95 \%$ \\
\hline Caladenia graniticola & 5 & 300 & $46 \%$ & $6 \%$ & $11 \%$ & $37 \%$ & 600 & 1 ha & $50 \%$ \\
\hline Caladenia melanema & 1 & 2270 & $41 \%$ & $8 \%$ & $22 \%$ & $40 \%$ & 5500 & 2 ha & $50 \%$ \\
\hline Drakaea isolata & 1 & 297 & $18 \%$ & NA & $29 \%$ & NA & 300 & 9 ha & $95 \%$ \\
\hline
\end{tabular}

*Total from population survey $x$ annual emergence rate. \# one plant has been located elsewhere.

\section{Modelling species distributions and anticipated climate threats}

Risk management approaches to deal with future climate scenarios in combination with other threats to rare orchids in their habitats (especially pollination, weeds and fire which interact with climate). Software such as BCCVL can be used to produce models of potential species distributions in the present or future using comprehensive datasets and expertise available for Australia and globally (bccvl.org.au). These maps can be used to guide surveys in the present and select sites for translocation based on future climate scenarios (if they exist). Orchid diversity mapping using programs such as Biodiverse (Laffan et al. 2011) allows orchid diversity hotspots to be recognised for conservation planning (Brundrett 2014, Phillips et al. 2010).

\section{Habitat management to reduce threats}

The key risks identified for orchids in WA include grazing, low rates of pollination and extremely small core habitat areas (Table 1). Core habitat areas are spatial polygons drawn to include all or almost all plants of a rare species to focus conservation actions (Brundrett 2016). Habitat management options that can be effective for protection rare orchid populations include weed management, reducing access, installing signs, or erecting fences (Brundrett 2016). Small fenced enclosures (Fig. 3D) substantially reduced grazing of rare wheatbelt orchids and cages effectively prevent loss of flowers of the glossy-leaved hammer orchid (Fig 3F). 


\section{Gathering essential data on the genetic diversity and taxonomy of orchid "species"}

There are major problems with species definitions in some orchid genera and this has resulted in many species in WA that cannot be reliably identified (Brundrett 2014, Brundrett \& Hammer 2020). Recent studies of the evolution of Australian terrestrial orchids have shown that many species have diverged relatively recently compared to other plant families (e.g. Nauheimer et al. 2018). Furthermore, DNA sequence data shows little or no genetic differences between species in orchid genera such as Thelymitra and Diuris (Indsto et al. 2009, Nauheimer et al. 2018). Resolving these problems requires integrated taxonomic and genetic studies, especially for rare orchids in species complexes where taxa seem to intergrade (orchids often hybridise). Species on rare flora lists that are very similar genetically to more common species divert resources from rare species that are much more distantly related to their sister taxa (Li et al. 2018). Powerful genetic tools are available for measuring evolutionary distances between orchid species and should be used to guide conservation planning (see Li et al. 2018).

A preliminary assessment suggests that over 70 of the 106 rare or priority orchid species in southwest WA belong to species complexes that include similar species that may intergrade (Mark Brundrett unpublished). For example, some populations of the Queen of Sheba orchid have intermediate floral features between Thelymitra variegata and T. speciosa (see Fig. 5) and occur where the distributions of these species overlap. If these are hybrids, then the only known remining true population of this species had 12 plants in 2019 (Andrew Webb pers. comm.). There are many other apparently rare WA orchids that urgently require integrated taxonomic and genetic studies.

\section{Pollinator studies by flower baiting and observations}

The flower-baiting method has often been used to detect effective pollinators of orchid species in natural habitats (Phillips et al. 2009, Menz et al. 2013, Bower 2015). This method utilises flowering plants in pots or picked flowers which are moved to potential orchid habitats to see if insects are attracted (see Fig. 4). This normally only works well for sexually deceptive orchid species and they must be relocated to a new spot after about 15 minutes because pollinators quickly learn to avoid them. It may not be possible to do this for many rare orchids due to limited numbers of flowers and long travel times to the remote locations where they grow. There also can be brief windows of pollinator availability due to temperature dependence and other factors (Kuiter 2015). Furthermore, it is not uncommon for orchids growing in locations where floral baiting results are negative to set seed anyway (Brundrett 2019). This suggests that even brief periods of pollinator availability, that are unlikely to be observed or detected by flower baiting, are sufficient for seed to form. Nevertheless, pollinator studies have been successfully used to guide translocation site selection in eastern Australia (Reiter et al. 2016). Some orchids are expected to have generalist pollination systems and their pollination may be linked to the presence of local non-orchid flowers they mimic (Scaccabarozzi et al. 2018, Brundrett 2019). This allows potential pollinators to be counted more easily and can be used to predict orchid pollination rates based on the diversity of other plants present and their associated insects.

\section{Manual pollination in natural populations}

Natural pollination rates of orchids are often very low in Western Australia, especially for species that rely on sexual or visual deception of insects and the majority of WA orchids belong to these categories (Scaccabarozzi et al. 2018, Brundrett 2019). Even relatively common orchids, such as Thelymitra species in Perth tend to have low average pollination rates (5-17\%), but their populations are sustainable due to greater pollination rates for isolated plants and the production of numerous flowers (Brundrett 2019). In contrast, extremely low pollination rates of some rare orchids are one of the most serious threats to their survival (Figs. 1A, 2BD, Table 1). Phillips et al. (2015) stated that "due to the low reproductive success of Caladenia huegelii, ongoing human intervention will almost certainly be needed to sustain the species". There have been no consistent attempts to follow up on this recommendation and a similar situation probably also applies to many other rare orchids in WA.

If pollination rates are low or extra seed is required for conservation of orchids, it is relatively easy to artificially cross-pollinate orchid flowers and attach seed bags (Fig. 6). It is unlikely that the vigour of orchid plants will be affected by this additional seed production, since flowering normally occurs after perennating 
structures such as tubers have already formed (Brundrett 2014). Seed bags prevent loss of seed due to dispersal and grazing by large animals or invertebrates. A thin translucent, porous and non-perishable fabric is used to cover forming seed capsules without excluding light required for photosynthesis (Vilene ${ }^{\mathrm{TM}}$ interfacing). Squares of this fabric are wrapped around pollinated flowers several times, secured with twist ties and anchored to a branch or stake as shown in Figures 6E-H and 7A. Orchid seed pod development is rainfall dependent and can be severely impacted by late spring drought (Brundrett 2019).

It should be noted that seed collection for long term storage or propagation for translocation requires different protocols than seed for research trials. Whenever possible the former two objectives require donor plants that represent the full range of floral variability and genetic diversity present in one or more populations, while the latter may only consist of seed from a few neighbouring plants. Studies of European orchids show that plants that grow in close proximity are usually very closely related (Ren et al. 2017, Hedrén \& Lorenz 2019). I suspect that many of the existing orchid seed in ex situ collections are from a limited number of donor plants so may not be suitable for translocation.

\section{Pollination followed by natural dispersal}

To overcome low rates of natural pollination, orchids are cross-pollinated as described above, but allowed to disperse naturally. This is the simplest and most inexpensive form of intervention, but may not be effective in all years due to climatic factors. Furthermore, orchid seed tends to fall close to parent plants (Jersáková \& Malinová 2007) and very low rates of germination can occur (see 11). An aggregated distribution of orchids may increase their risks of grazing, human impacts, etc. and would also cause greater intraspecific competition for pollinators, light and nutritional resources provided by associated fungi (Brundrett 2016, 2019). For these reasons it is advisable to disperse seeds manually over larger areas, but these should be marked with stakes or tags so germination rates can be estimated.

\section{Pollination followed by local placement in situ}

This also requires artificial pollination as described in 9 above, but small aliquots of seed are placed on or into soil next to markers or in pouches, so seedlings can be counted. Small seed batches can be produced by dilution in clean fine sand or water (with a drop of detergent). This approach has been used for rare and common orchids in Perth (see Appendix 2). Seed translocations have established new orchid populations in eastern Australia (Wright et al. 2007) and Europe (De Hert et al. 2013). However, site preparation (localised soil disturbance) increased the germination of seedlings and their subsequent survival was very strongly linked to leaf size in the first year (Wright et al. 2007). Seed germination in situ can also be increased by fungal inoculation (Batty et al. 2006b). In situ seed germination on tree bark also works for tropical epiphytic orchids using pouches of fungus-inoculated peat moss (Shao et al. 2017).

\section{Seed baiting to locate compatible fungi and suitable habitats}

Orchids have relatively specific mycorrhizal fungal associates required for seed germination and the survival of adult plants (Rasmussen \& Rasmussen 2009, Zettler \& Corey 2018, Oktalira et al. 2019). These are even more important for those Australian terrestrial orchids which lack roots (Brundrett 2014). Orchid seed baiting detects compatible fungi in soils, but seed germination is often highly variable (Batty et al. 2001a, Brundrett et al. 2003, Diez et al. 2007). In situ seed baiting utilises seed enclosed in nylon mesh pouches buried in the soil to measure germination (Rasmussen \& Whigham 1993, Brundrett et al. 2003). This method has also been adapted for epiphytic orchids (Izuddin et al. 2019). Ex situ seed germination was successful with orchids from 6 different genera in WA (Brundrett et al. 2003) and tubers sometimes formed within pouches (Batty et al. 2001a). Ex situ seed baiting utilises orchid seed paced over soil organic material from natural habitats incubated under controlled conditions (Fig. 8). This method avoids issues with climatic conditions and makes it easier to obtain mycorrhizal fungi from protocorms. Both methods have been used to screen potential translocation sites for presence of compatible fungi (Brundrett \& Ager 2011, De Hert et al. 2013, Reiter et al. 2016). They can also be used with DNA sequencing to identify fungi without destructive sampling of adult plants. DNA-based methods also can be used to detect mycorrhizal fungi in soils directly, but results can be challenging to interpret (Bougoure et al. 2008, Egidi et al. 2018, Kaur et al 2019). All of these methods have found orchid fungi to be more widespread than associated orchids. 


\section{Vegetative propagation}

Vegetative division by tuber multiplication in pots can be used to effectively propagate some orchids in living collections. I have also observed that some Australian orchids can be propagated from a small piece of root tubers without substantial harm to existing plants. However, it would be difficult to produce sufficient material for a translocation using these methods.

\section{Non-sterile symbiotic propagation methods}

An efficient new nonsterile germination method was developed by Brundrett \& Agar (2011). It requires nonsterile organic material containing compatible fungi which resulting from ex situ seed baiting. This organic material was used to inoculate pasteurised orchid potting mix where orchid seeds were sown in germination pouches (Fig. 9). This is a relatively fast and efficient method of growing orchids (Table 2) and seedlings were of sufficient size for translocation within 1 year (Fig. 9). Seedling morality in potting mix was low, presumably because they were pre-adapted for growth in the presence of soil organisms. Other cases where non-sterile germination of orchid seeds has also been successful include:

1. Tropical epiphytic orchids by encapsulating seeds and fungi in alginate beads placed in a nonsterile moss (Bayman 2012).

2. A tropical terrestrial orchid in non-sterile peat or coco-peat inoculated with compatible fungi (Aewsakul et al. 2013).

3. Gastrodia sp., a myco-heterotrophic (non-green) orchid, in leaf litter that naturally that contains compatible fungi (Higaki et al. 2017).

4. The underground orchid (Rhizanthella gardneri) under a secondary host (Melaleuca spp.) by inoculation of seeds with fungi encapsulated in agar beads (Bougoure et al. 2010).

5. Australian terrestrial orchids in potting mix inoculated with millet seed colonised by a fungus (Nesbitt 2004, Wright et al. 2009).

6. Australian terrestrial orchids by sprinkling seed under plants growing in pots (Wright et al. 2009). Most studies reported that orchid propagation was substantially faster and easier in non-sterile systems than using sterile culture methods, but further trials are required to increase the consistency and applicability of these methods (Brundrett \& Agar 2011, Bayman 2012, Aewsakul et al. 2013). A semi-sterile method where axenically grown protocorms are transferred to sand over agar for further growth can also be very successful for acclimating seedlings before growth in nature (Batty et al. 2006a).

\section{Symbiotic germination in sterile culture}

These standard protocols are the most commonly used method for propagating orchids in Australia for many years (e.g. Warcup 1973, Batty et al. 2006b, Wright et al. 2009, Reiter et al. 2018). Compatible mycorrhizal fungi from axenic culture and surface sterilised orchid seeds are combined on petri plates (Fig. 10). These fungi are usually isolated from adult plants and can be maintained in culture for months or years (Brundrett et al. 2001, Zettler \& Corey 2018). This method requires well-maintained, fully sterile facilities for preparing media, sterilising seeds, starting germination and maintaining seedlings (Table 2, Brundrett et al. 2001, Thomson 2002). Small outplanted seedlings produced this way can have high rates of attrition caused by drought and grazing, with invertebrates as a major culprit (Scade et al. 2006). Consequently, 2-3 years of growth in the laboratory and greenhouse is required for seedlings with substantial tubers to produce resilient plants (Reiter et al. 2016). Comprehensive instructions and advice about use of these methods and subsequent seedling care from is provided by Brundrett et al. (2001) and Thomson (2002, 2003). 


\section{Asymbiotic seed germination or clonal propagation in sterile culture}

Asymbiotic orchid seed germination uses a complex sterile culture media without fungal inoculum. This media can be formulated in a laboratory or purchased in packet form. These methods are relatively straightforward, but require a sterile culture laboratory and incubators (Fig. 11). They can be very successful for some orchids (e.g. Bustam et al. 2014), but attrition rates can be high after deflasking into non-sterile potting mix (see Thomson 2003). A comparison of growth rates for orchid protocorms using different culture methods revealed that protocorms grew at about $1 / 2$ the rate of seedlings in nonsterile systems and it takes up to 3 years to get plants large enough for outplanting (Table 2 ).

Micropropagation of orchids (methods based on clonal division rather than seed germination) are now the main form of propagation used for commercial orchid production (Yam \& Arditti 2009). These methods have been perfected for some Australian orchids (e.g. Collins \& Dixon 1992, Bustam et al. 2017), but tend to require more specific formulation than media for seed germination (Yam \& Arditti 2009). They allow specific cultivars of orchids to be cloned on large scale, but are less well suited to orchid conservation, where maintaining genetic diversity is usually a key issue. Nevertheless, there is a great potential to micropropagate selected cultivars of rare orchids commercial sales to take pressure of wild plants.

\section{Translocation}

"Translocation is the deliberate transfer of plants or regenerative plant material from an ex situ collection or natural population to a new location, usually in the wild. It includes reintroduction, introduction, reinforcement, assisted migration and assisted colonization" (Commander et al. 2018). The majority of rare flora translocations within Australia have either not been successful, are poorly documented, or include limited genetic diversity (Silcock et al. 2019). There have been 22 or more orchid translocation in Australia with documentation, where establishment was successful in 18 of them, seed set occurred in 14 and recruitment of new seedlings was observed in 4 (Reiter et al. 2016, Reiter \& Thompson 2018). Only two of these are in WA and it is not known how many orchid translocations in WA have been successful overall. The success rate for orchid translocation is highly dependent on the number of individuals involved, their size and careful site selection (Smith et al. 2009, Reiter et al. 2016). Expected attrition rates need to be factored into translocation plans and effective measures taken to protect seedlings.

Some translations involve adult orchid plants rescued from development sites (e.g. Liu et al. 2012). It has also been recommended that some rare orchids in dense populations be relocated to new sites to avoid impacts of overcrowding (Wright et al. 2009, Brundrett 2016). Plant density has major impact on orchid pollination rates in WA (Brundrett 2019). During translocations, groups of new plants should be positioned relative to each other and any existing plants to maximise genetic connectivity (see Appendix 3 ). This requires spacing distances between groups based on the behaviour of pollinators.

Translocations are relatively expensive and time consuming relative to some of the other options discussed above and, in some cases, have had low long-term success rates (Zimmer et al. 2019). They may also require a longer lead in time to gain approval from regulators. As explained above, there are a substantial number of rare orchids, both in WA and globally, including species which are at high risk of extinction in the short term. Consequently, conservation actions must be both highly effective and cost and labour efficient. The most efficient approach would be to produce a generic translocation proposal for all terrestrial orchids in a region such as WA, since the approaches required will be very similar in all cases. This could consist of a series of modules similar to those provided in Appendix 1,2 and 3. This approach allows each module to receive a one-off scientific review to streamline future approvals processes. There would also be some genus or species-specific information required that could be reviewed as a separate short document with specific data on one or more orchids. Including multiple orchids in recovery plans and translocation proposals is the standard approach in some jurisdictions. For example, 12 Caladenia species are included in one recovery plan for eastern Australia (Todd 2000). 


\section{Tuber banks, commercial availability and seed banks}

Ex situ seed storage is an important failsafe mechanism for conservation of threatened orchid species (Batty et al 2001b, Neto \& Custódio 2005). However, this may require seed to be sourced from a wider range of plants than normally occurs, since existing rare orchid seed in ex situ storage often comes from relatively few plants (see above). Combining orchid seeds with compatible fungi in agar beads is recommended for their long-term storage (Sommerville et al. 2008).

Rare orchids have been illegally removed from the wild in WA and this is one of the main threats to all rare Australian orchids (Wraith \& Pickering 2019). It is almost impossible to prevent this by guarding their habitats or trying to keep them secret. The best approach to reduce orchid theft is for rare orchids to become commercially available to take pressure of existing plants in nature (Nash et al. 2003, Hinsley et al. 2018). Ex situ conservation in living collections has been very effective in eastern Australia (called tuber banks) and is a consequence of the availability of plants to experienced orchid growers. These plants also function as seed orchards to restock natural habitats. Many orchids have been successfully maintained for decades in a tuber bank managed by the Australian Native Orchid Society (Link).

Long term care of rare terrestrial orchids in ex situ living collections can be labour intensive and challenging due to higher rates of mortality in some orchids and diseases that can spread within collections. For example, rust fungi are endemic in many wild populations of Thelymitra spp. and can spread in collections. Viruses are very common in WA orchids and can be readily spread by insects within collections (Wylie et al. 2013). For this reason, it is important to screen orchids that have been grown in living collections for diseases before returning them to the wild. A better approach would be to propagate new orchids from seeds and keep seedlings that are being grown for translocation in isolation from other orchids.

\section{Communication activities and use of iconic orchids in ecotourism}

Promotion and communication activities to promote rare orchid conservation are essential to attract political support, funding and volunteers. Communication also needs to reflect the knowledge and experience of all stakeholders, especially scientists and volunteers. It is also important to incorporate the knowledge of volunteers and scientists into decision making processes by government departments. Finally, positive conservation experiences and the promotion of outcomes are also an ideal basis for sustainable ecotourism programs. These programs have massive potential for helping to fund conservation, but land managers and conservation agencies are also hesitant to allow the public access to very rare species. There also can be reluctance to make rare species commercially available through orchid growers, even when this is essential for their conservation. The efficient propagation of rare orchids can solve these problems by creating new publicly accessible populations of rare species and greatly reducing the value of orchids stolen from the wild.

Thus, the main objectives for propagation of orchids should be to reintroduce them to former habitats and also create locations where they can be photographed by orchid enthusiasts without impacting on natural populations. For example, Thelymitra variegata is one of the most beautiful terrestrial orchids on earth (see Fig. 5). It was formerly widespread in the Perth area, but has become locally extinct within recent decades, due primarily to habitat loss. There were 21 collections of Thelymitra variegata in Perth localities between 1900 and 1959, but no records since then (www.ala.org.au, accessed: 15-3-2020). There are also major concerns about closely related species in the Thelymitra variegata group, which are very popular with orchid enthusiast and have been stolen from their habitats ( $T$. apiculata and $T$. pulcherrima). It is essential to develop an effective conservation and ecotourism project focussing on all these orchids, since the approaches required will be very similar for all of them.

\section{Conclusions}

The relative efficiency, cost and time required of alternative orchid propagation methods should be considered before choosing which one(s) to use for orchid conservation (Table2, Fig. 12C). There are many published scientific studies on specific orchid propagation methods, but comparisons of different methods for the same species are difficult to find. Germination rate data are most often used to summarise outcomes, but may be less relevant than other metrics if seeds are not in short supply. Seedling growth rates and/or 
their survival after outplanting are the most important indicators of the effectiveness of methods. Seedling growth data are rarely published, but there often is an indication of how long germination takes overall. However, studies are difficult to compare since they use different protocorm growth stages to indicate successful germination (Collins 2004). I found one case study comparing non-sterile and asymbiotic sterile germination (Brundrett \& Ager 2011) and another comparing symbiotic and asymbiotic germination in culture (Bustam et al. 2014). Both of these studies used one or more Caladenia species, but only the former includes protocorm and seedling growth rate data (see Table 2).

Comparing the efficiency of methods is also made more difficult because scientific papers do not take preliminary trials required to optimise methods into account, so overall seed use efficiency cannot be determined. Furthermore, seed density influences the germination, growth and survival of seedlings (Rasmussen et al. 1989), so may also determine seed use efficiency. Cost-benefit analyses should include the relative expense, complexity, training required, required facilities for initiation and growth of seedlings and overall time taken (including preparation of fungal cultures, seeds and media) when comparing methods (Table 2, Fig. 12C). Another key factor is the ability for genetic diversity to be maintained during orchid propagation. This is less likely to be achieved if clonal culture methods are used (these are used to maintaining floral consistency in orchid cultivars). There is more potential to include genetic diversity using in vitro seed germination methods, but here is a risk that fungal specificity or growing conditions will favour some orchid genotypes over others. In contrast, in situ seed sowing may be the most effective method for maintaining genetic diversity, due to natural growing conditions.

Table 2. Comparisons of time required, cost and the seed germination efficiency of orchid propagation methods (Brundrett \& Ager 2011).

\begin{tabular}{|c|c|c|c|c|c|}
\hline & $\begin{array}{l}\text { In situ seed } \\
\text { baiting or } \\
\text { sowing }\end{array}$ & $\begin{array}{l}\text { Ex situ seed } \\
\text { baiting }\end{array}$ & $\begin{array}{l}\text { Non-sterile } \\
\text { propagation in } \\
\text { seed packets }\end{array}$ & $\begin{array}{l}\text { Symbiotic } \\
\text { germination on } \\
\text { sterile media }\end{array}$ & $\begin{array}{l}\text { Asymbiotic } \\
\text { germination on } \\
\text { sterile media }\end{array}$ \\
\hline Germination rate & $0-10 \%^{1}$ & $0-30 \%$ & $0-90 \%$ & $0-70 \%^{2}$ & $0-93 \%^{3}$ \\
\hline Seedling growth rate $\left(\mathrm{mm}\right.$ week $\left.^{-1}\right)$ & NA & 0.05 & 0.1 & NA & 0.04 \\
\hline Relative cost (financial) & Nil & low & low & high & high \\
\hline Preparation time (days) & 0.5 & 4 & 3 & 6 & 4 \\
\hline $\begin{array}{l}\text { Multiplies fungus inoculum with } \\
\text { seedlings }\end{array}$ & no & yes & yes & no & no \\
\hline Complexity of methods & low & medium & low & high & high \\
\hline Time to produce seedlings & 6 months & $1-2$ months & $1-2$ months & 2-4 months & 2-6 months \\
\hline Survival in field or greenhouse & NA & medium & high & low or high & low or high \\
\hline Overall Ranking & $* *$ & $* *$ & $* * * *$ & $* *$ & $* * *$ \\
\hline
\end{tabular}

Data sources: 1. De Hert et al 2013, 2. literature review, 3. Bustam et al. 2014.

The propagation of orchid seedlings is a long and labour-intensive process and there is an inverse relationship between seed germination rates and the time required or cost of methods (Table 2). A survey of relevant scientific literature suggests there is a tendency to use relatively complex and expensive methods for orchid propagation. This may be caused by preconceived ideas, or because they produce data suited for scientific publication. Less complex approaches such as in situ seed sowing or non-sterile germination are used infrequently, even though they can be very effective and are much more cost effective (Fig 12C). All methods require optimisation for new orchid species, but less is known about the reliability and optimisation of optimise less complex methods. Thus, it is advisable to use multiple approaches to propagate rare orchids to maximise the possibility that at least one method will be successful. This involves trialling different methods on a small scale and continuing those which work best (following an adaptive management framework). In situations when site access is very difficult, or funding is very limited, simple recovery methods can still be used if complex methods are not possible (e.g. harvesting and placing seed in situ on the same day).

A proposed adaptive management framework for conserving rare orchids is outlined in Figure 12 . This approach requires recovery actions to be flexible enough to respond to specific orchid or habitat-based issues after initial propagation, seeding and/or outplanting results are obtained. Flexible approaches to 
conservation are more likely to succeed with orchids than other plants due to the very large number of seeds they produce, which can easily be augmented by hand pollination. They also have mycorrhizal fungi, needed to trigger their germination and sustain their growth, which are far more widespread than the orchids they occupy. Thus, conservation actions for orchids should be designed to take advantage of their unique biological features, but also need to be tailored to address species or habitat specific problems that can only be overcome by research.

\section{References}

Aewsakul N, Maneesorn D, Serivichyaswat P, Taluengjit A, Nontachaiyapoom S (2013) Ex vitro symbiotic seed germination of Spathoglottis plicata Blume on common orchid cultivation substrates. Scientia Horticulturae 160, 238-242.

Batty A, Brundrett MC, Dixon K, Sivasithamparam K (2006a) New methods to improve symbiotic propagation of temperate terrestrial orchid seedlings from axenic culture to soil. Australian Journal of Botany 54, 367-374. (Link)

Batty AL, Brundrett MC, Dixon KW, Sivasithamparam K (2006b) In situ symbiotic seed germination and propagation of terrestrial orchid seedlings for establishment at field sites. Australian Journal of Botany 54, 375-381.

Batty AL, Dixon KW, Brundrett MC, Sivasithamparam K (2001a) Constraints to symbiotic germination of terrestrial orchid seed in a mediterranean bushland. New Phytologist 152, 511-520. (Link)

Batty AL, Dixon KW, Brundrett MC, Sivasithamparam K (2001b) Long-term storage of mycorrhizal fungi and seed as a tool for the conservation of endangered Western Australian terrestrial orchids. Australian Journal of Botany 49, 619-628. (Link)

Bayman P (2012) Growing epiphytic orchids from seed: A simple, nonsterile, symbiotic method. Orchids (Linleyana) 81, 564-567.

Bougoure J, Brundrett M, Brown A, Grierson PF (2008) Habitat characteristics of the rare underground orchid Rhizanthella gardneri. Australian journal of botany 56, 501-511.

Bougoure JJ, Brundrett MC, Grierson PF (2010) Carbon and nitrogen supply to the underground orchid, Rhizanthella gardneri. New Phytologist 186, 947-956.

Bower CC (2015) Pollinator sharing by the sexually deceptive Green-comb Spider Orchids, Caladenia phaeoclavia, C. parva and C. villosissima (Orchidaceae: Caladeniinae): taxonomic considerations. Telopea 18, 309-323.

Brundrett MC (2007) Scientific approaches to Australian temperate terrestrial orchid conservation. Australian Journal of Botany 55, 293-307. (Link)

Brundrett MC (2016) Using vital statistics and core-habitat maps to manage critically endangered orchids in the Western Australian wheatbelt. Australian Journal of Botany 64, 51-64. (Link)

Brundrett MC (2019) A comprehensive study of orchid seed production relative to pollination traits, plant density and climate in an urban reserve in Western Australia. Diversity 11, 123. (link)

Brundrett M (2014) 'Identification and Ecology of Southwest Australian Orchids.' (Western Australian Naturalists' Club Inc.)

Brundrett M, Ager E (2011) Wheatbelt Orchid Rescue Project Final Report: Seed Collecting, Soil Baiting and Propagation of Orchids. The University of Western Australia, (Nedlands WA) (Link).

Brundrett M, Hammer T (2020) The Eriochilus dilatatus (Orchidaceae) complex in Western Australia: subspecies taxonomy is not supported by consistent differences in morphology or distribution. Australian Systematic Botany 33, 329-345.

Brundrett M, Scade A, Batty A, Dixon K, Sivasithamparam K (2003) Development of in situ and ex situ seed baiting techniques to detect mycorrhizal fungi from terrestrial orchid habitats. Mycological Research 107, 1210-1220. (Link)

Brundrett M, Sivasithamparam K, Ramsay M, Krauss S, Taylor R, Bunn E, Hicks A, Karim N, Debeljak N, Mursidawati S, others (2001) 'Orchid Conservation Techniques Manual.' (First International Orchid Conservation Congress: Kings Park, Western Australia) (Link) 
Bustam BM, Dixon KW, Bunn E (2014) In vitro propagation of temperate Australian terrestrial orchids: revisiting asymbiotic compared with symbiotic germination. Botanical Journal of the Linnean Society 176, 556-566.

Bustam BM, Dixon K, Bunn E (2017) Ex situ germplasm preservation and plant regeneration of a threatened terrestrial orchid, Caladenia huegelii, through micropropagation and cryopreservation. Australian Journal of Botany 64, 659-663.

Collins MT (2004) How do you determine when orchid seed germination has been successful? The Orchadian 15, 60-71.

Collins MT, Dixon KW (1992) Micropropagation of an Australian terrestrial orchid Diuris longifolia R. Br. Australian Journal of Experimental Agriculture 32, 131-135.

Commander LE, Coates DJ, Broadhurst L, Offord CA, Makinson RO, Matthes M (2018) 'Guidelines for the Translocation of Threatened Plants in Australia.' (Australian Network for Plant Conservation Incorporated) (Link)

De Hert K, Jacquemyn H, Provoost S, Honnay O (2013) Absence of recruitment limitation in restored dune slacks suggests that manual seed introduction can be a successful practice for restoring orchid populations. Restoration Ecology 21, 159-162.

Diez JM (2007) Hierarchical patterns of symbiotic orchid germination linked to adult proximity and environmental gradients. Journal of Ecology 95, 159-170.

Egidi E, May TW, Franks AE (2018) Seeking the needle in the haystack: Undetectability of mycorrhizal fungi outside of the plant rhizosphere associated with an endangered Australian orchid. Fungal Ecology 33, 13-23.

Gale SW, Fischer GA, Cribb PJ, Fay MF (2018) Orchid conservation: bridging the gap between science and practice. Botanical Journal of the Linnean Society 186, 425-434.

Hedrén M, Lorenz R (2019) Seed dispersal and fine-scale genetic structuring in the asexual Nigritella miniata (Orchidaceae) in the Alps. Botanical Journal of the Linnean Society 190, 83-100.

Higaki K, Rammitsu K, Yamashita Y, Yukawa T, Ogura-Tsujita Y (2017) A method for facilitating the seed germination of a mycoheterotrophic orchid, Gastrodia pubilabiata, using decomposed leaf litter harboring a basidiomycete fungus, Mycena sp. Botanical studies 58, 1-7 (59).

Hinsley A, De Boer HJ, Fay MF, Gale SW, Gardiner LM, Gunasekara RS, Kumar P, Masters S, Metusala D, Roberts DL (2018) A review of the trade in orchids and its implications for conservation. Botanical Journal of the Linnean Society 186, 435-455.

Indsto JO, Weston PH, Clements MA (2009) A molecular phylogenetic analysis of Diuris (Orchidaceae) based on AFLP and ITS reveals three major clades and a basal species. Australian systematic botany 22, 1-15.

Izuddin M, Yam TW, Webb EL (2019) Germination niches and seed persistence of tropical epiphytic orchids in an urban landscape. Journal of Plant Research 132, 383-394.

Jersáková J, Malinová T (2007) Spatial aspects of seed dispersal and seedling recruitment in orchids. New Phytologist 176, 237-241.

Kaur J, Andrews L, Sharma J (2019) High specificity of a rare terrestrial orchid toward a rare fungus within the North American tallgrass prairie. Fungal Biology 123, 895-904.

Kuiter RH (2015) 'Orchid Pollinators of Victoria.' (Aquatic Photographics: Seaford, Victoria)

Laffan SW, Lubarsky E, Rosauer DF (2010) Biodiverse, a tool for the spatial analysis of biological and related diversity. Ecography 33, 643-647.

Li J, Gale SW, Kumar P, Zhang J, Fischer G (2018) Prioritizing the orchids of a biodiversity hotspot for conservation based on phylogenetic history and extinction risk. Botanical Journal of the Linnean Society 186, 473-497.

Liu H, Feng C-L, Chen B-S, Wang Z-S, Xie X-Q, Deng Z-H, Wei X-L, Liu S-Y, Zhang Z-B, Luo Y-B (2012) Overcoming extreme weather challenges: successful but variable assisted colonization of wild orchids in southwestern China. Biological Conservation 150, 68-75. 
Marshall D, Pritchard A, Duncan M (2005) The Success of government-community group partnerships in orchid conservation in Victoria, Australia. Selbyana 293-298.

Menz MH, Phillips RD, Dixon KW, Peakall R, Didham RK (2013) Mate-searching behaviour of common and rare wasps and the implications for pollen movement of the sexually deceptive orchids they pollinate. PLoS One 8, e59111.

Nash N, Barrett RL, Oakely HF, Chalmers I, Richards H (2003) Role of orchid societies and growers in conservation. 'Orchid Conservation'. pp. 313-328. (Natural History Publications: Kota Kinabalu, Sabah, Malaysia)

Nauheimer L, Schley RJ, Clements MA, Micheneau C, Nargar K (2018) Australasian orchid biogeography at continental scale: molecular phylogenetic insights from the sun orchids (Thelymitra, Orchidaceae). Molecular phylogenetics and evolution.

Nesbitt L (2004) Growth of fungus dependent terrestrial orchids. The Orchadian 15, 102-107.

Neto NBM, Custódio CC (2005) Orchid conservation through seed banking: ins and outs. Selbyana 229-235.

Office of the Auditor General Western Australia (2017) Rich and Rare: Conservation of Threatened Species Follow-up Audit. Office of the Auditor General Western Australia, (Perth, WA) https://audit.wa.gov.au/reports-and-publications/reports/rich-rare-conservation-threatened-speciesfollow-audit/auditor-generals-overview/.

Oktalira FT, Whitehead MR, Linde CC (2019) Mycorrhizal specificity in widespread and narrow-range distributed Caladenia orchid species. Fungal Ecology 42, 100869.

Phillips RD, Brown AP, Dixon KW, Hopper SD (2011) Orchid biogeography and factors associated with rarity in a biodiversity hotspot, the Southwest Australian Floristic Region. Journal of Biogeography 38, 487501.

Phillips RD, Faast R, Bower CC, Brown GR, Peakall R (2009) Implications of pollination by food and sexual deception for pollinator specificity, fruit set, population genetics and conservation of Caladenia (Orchidaceae). Australian Journal of Botany 57, 287-306.

Phillips R, Peakall R, Retter B, Montgomery K, Menz M, Davis B, Hayes C, Brown G, Swarts N, Dixon K (2015) Pollinator rarity as a threat to a plant with a specialized pollination system. Botanical Journal of the Linnean Society 179, 511-525.

Rasmussen H, Johansen B, Andersen TF (1989) Density-dependent interactions between seedlings of Dactylorhiza majalis (Orchidaceae) in symbiotic in vitro culture. Physiologia Plantarum 77, 473-478.

Rasmussen HN, Rasmussen FN (2009) Orchid mycorrhiza: implications of a mycophagous lifestyle. Oikos 118, 334-345.

Rasmussen HN, Whigham DF (1993) Seed ecology of dust seeds in situ: a new study technique and its application in terrestrial orchids. American Journal of Botany 80, 1374-1378.

Reiter N, Lawrie AC, Linde CC (2018) Matching symbiotic associations of an endangered orchid to habitat to improve conservation outcomes. Annals of Botany 122, 947-959.

Reiter N, Thomson R (2018) Involvement in the Royal Botanic Gardens Victoria's Orchid conservation program by volunteers from the Australasian Native Orchid Society Victoria Group. Australasian Plant Conservation: Journal of the Australian Network for Plant Conservation 27, 19.

Reiter N, Whitfield J, Pollard G, Bedggood W, Argall M, Dixon K, Davis B, Swarts N (2016) Orchid reintroductions: an evaluation of success and ecological considerations using key comparative studies from Australia. Plant Ecology 217, 81-95.

Ren M-X, Cafasso D, Cozzolino S, Pinheiro F (2017) Extensive genetic differentiation at a small geographical scale: reduced seed dispersal in a narrow endemic marsh orchid, Anacamptis robusta. Botanical Journal of the Linnean Society 183, 429-438.

Scaccabarozzi D, Cozzolino S, Guzzetti L, Galimberti A, Milne L, Dixon KW, Phillips RD (2018) Masquerading as pea plants: behavioural and morphological evidence for mimicry of multiple models in an Australian orchid. Annals of Botany. 
Scade A, Brundrett M, Batty A, Dixon K, Sivasithamparam K (2006) Survival of transplanted terrestrial orchid seedlings in urban bushland habitats with high or low weed cover. Australian Journal of Botany 54, 383 389. (Link)

Shao S-C, Burgess KS, Cruse-Sanders JM, Liu Q, Fan X-L, Huang H, Gao J-Y (2017) Using in situ symbiotic seed germination to restore over-collected medicinal orchids in Southwest China. Frontiers in Plant Science $8,888$.

Silcock JL, Simmons CL, Monks L, Dillon R, Reiter N, Jusaitis M, Vesk PA, Byrne M, Coates DJ (2019) Threatened plant translocation in Australia: A review. Biological Conservation 236, 211-222.

Smith ZF, James EA, McDonnell MJ, McLean CB (2009) Planting conditions improve translocation success of the endangered terrestrial orchid Diuris fragrantissima (Orchidaceae). Australian Journal of Botany 57, 200-209.

Sommerville KD, Siemon JP, Wood CB, Offord CA (2008) Simultaneous encapsulation of seed and mycorrhizal fungi for long-term storage and propagation of terrestrial orchids. Australian Journal of Botany 56, 609615.

Thomson D (2002) Growing terrestrial orchids from seed. The Orchadian 13, 473-476.

Thomson D (2003) Deflasking temperate terrestrial orchids. The Orchadian 14, 395-403.

Todd J (2000) Recovery Plan for twelve threatened Spider-orchid Caladenia taxa (Orchidaceae: Caladeniinae) of Victoria and South Australia 2000-2004. Department of Natural Resources and Environment, Melbourne.

Warcup JH (1973) Symbiotic germination of some Australian terrestrial orchids. New Phytologist 72, 387392.

Whigham DF, Willems JH (2003) Demographic studies and life-history strategies of temperate terrestrial orchids as a basis for conservation. Orchid conservation.

Wraith J, Pickering C (2019) A continental scale analysis of threats to orchids. Biological conservation 234, 717.

Wright M, Cross R, Dixon K, Huynh T, Lawrie A, Nesbitt L, Pritchard A, Swarts N, Thomson R (2009) Propagation and reintroduction of Caladenia. Australian Journal of Botany 57, 373-387.

Wright M, French G, Cross R, Cousens R, Andrusiak S, McLean CB (2007) Site amelioration for direct seeding of Caladenia tentaculata improves seedling recruitment and survival in natural habitat. Lankesteriana International Journal on Orchidology 7, 430-432.

Wright M, Thomson R, Smith Z, McQualter E, Cross R, others (2006) Royal Botanic Gardens Melbourne contributes to Victorian orchid conservation: ex situ propagation with mycorrhizal fungi. Australasian Plant Conservation 15, 12.

Wylie SJ, Li H, Dixon KW, Richards H, Jones MG (2013) Exotic and indigenous viruses infect wild populations and captive collections of temperate terrestrial orchids (Diuris species) in Australia. Virus research 171, 22-32.

Yam TW, Arditti J (2009) History of orchid propagation: a mirror of the history of biotechnology. Plant Biotechnology Reports 3, 1.

Zettler LW, Corey LL (2018) Orchid Mycorrhizal Fungi: Isolation and Identification Techniques. 'Orchid Propagation: From Laboratories to Greenhouses-Methods and Protocols'. pp. 27-59. (Springer).

Zimmer HC, Auld TD, Cuneo P, Offord CA, Commander LE (2020) Conservation translocation-an increasingly viable option for managing threatened plant species. Australian Journal of Botany 67, 501-509. 
Figure 1. Caladenia melanema vital statistics (A) and dormancy periods (B)

A

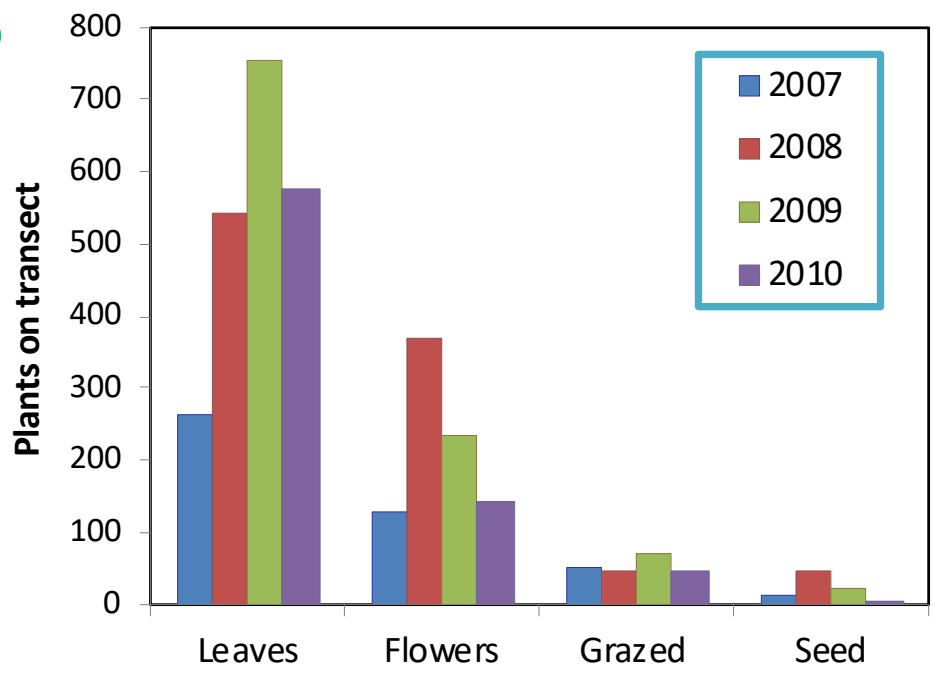

B

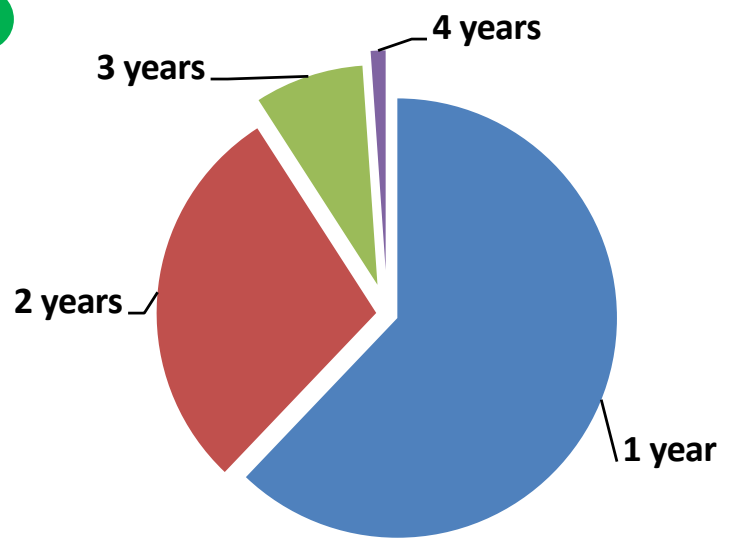

Figure 2. Caladenia huegelii population sizes (A) and vital statistics (B) Drakaea elastica population sizes (C) and vital statistics (D)
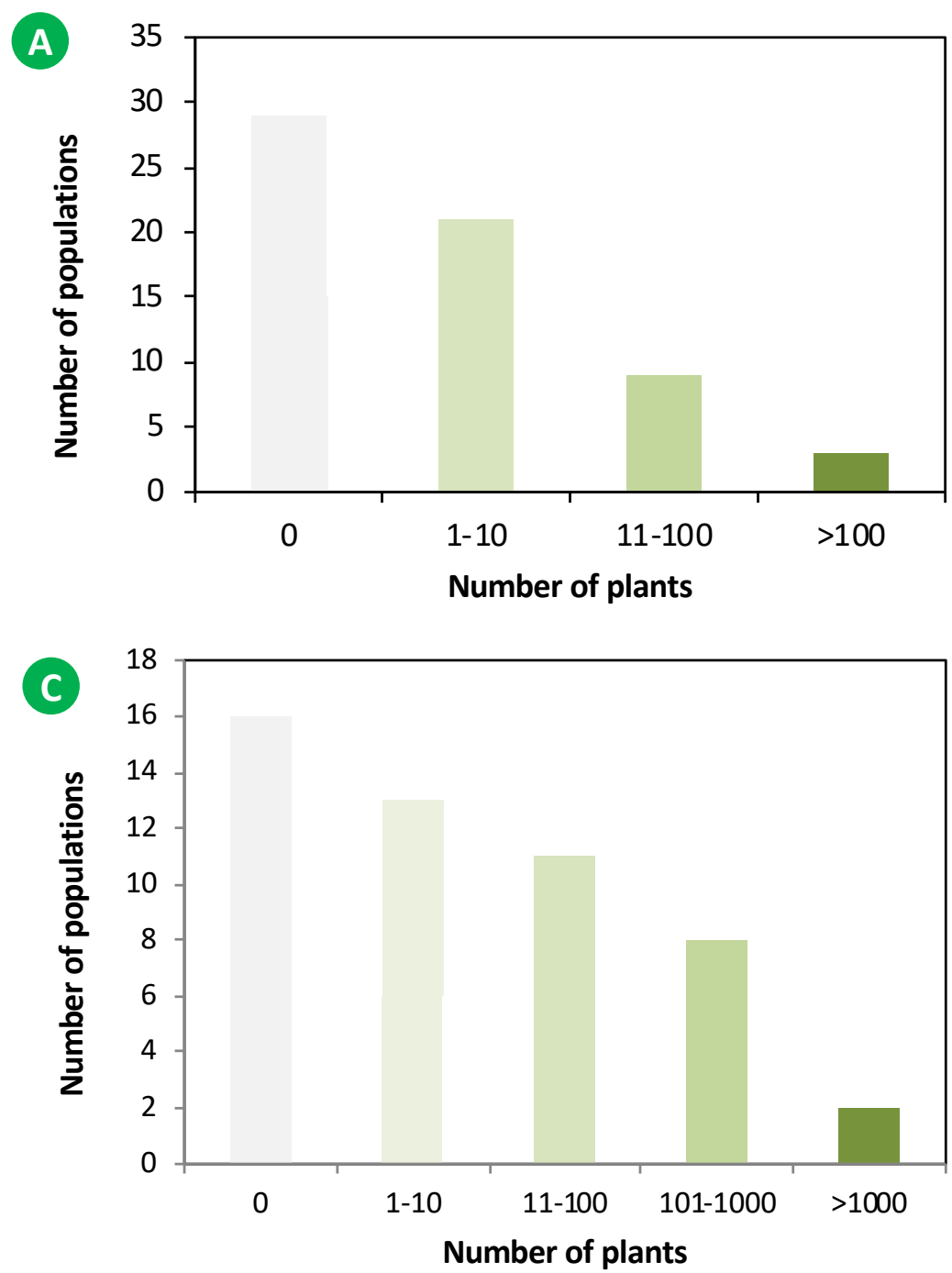

B

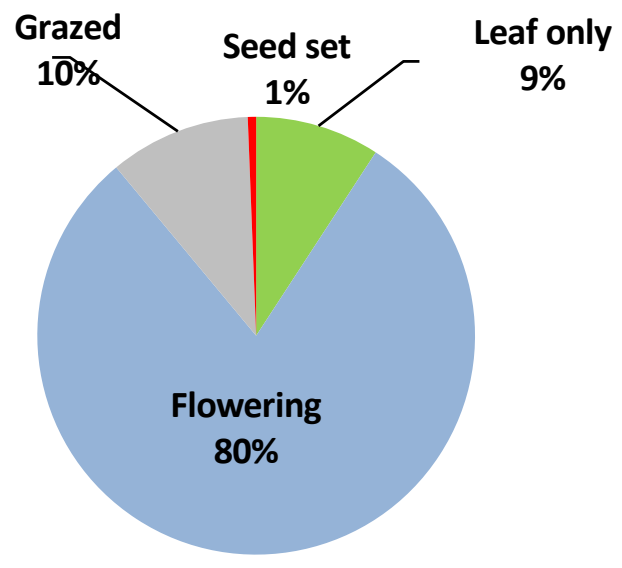

2017 data from largest population (163 plants)

D

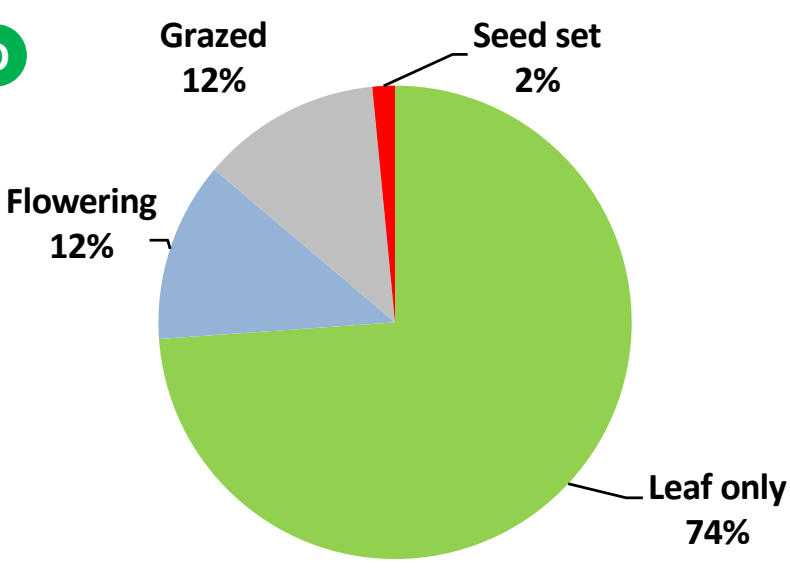

Data from populations surveyed in 2017 (1627 leaves) 
Figure 3. Caladenia melanema monitoring transect (A), grazing (B), pollination (C), and protection by fencing (D). Drakaea elastica leaves and grazed flowers (E), caged plants (F) and flower (G).

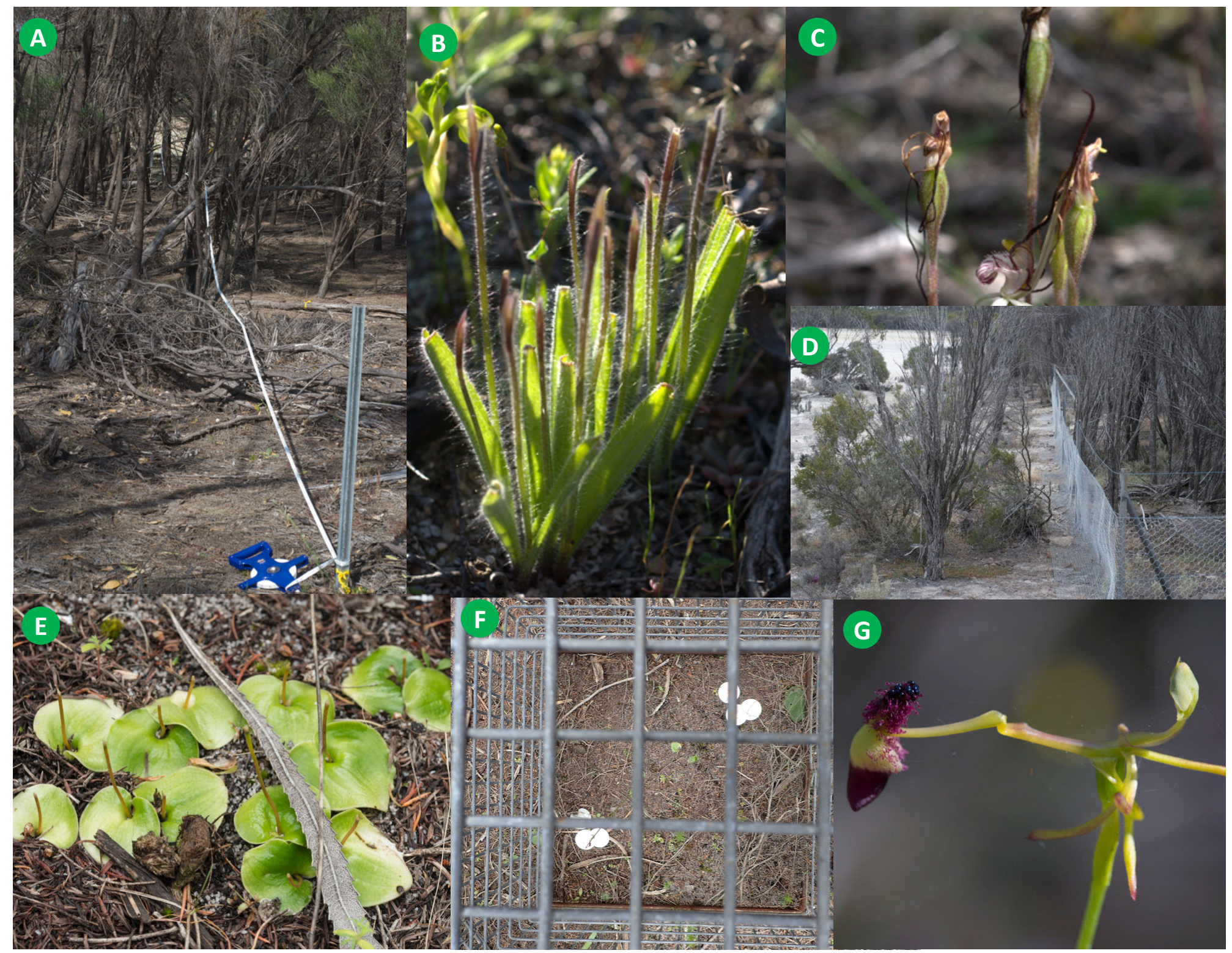

Figure 4. Pollination of Caladenia arenicola by a thynnine wasp.

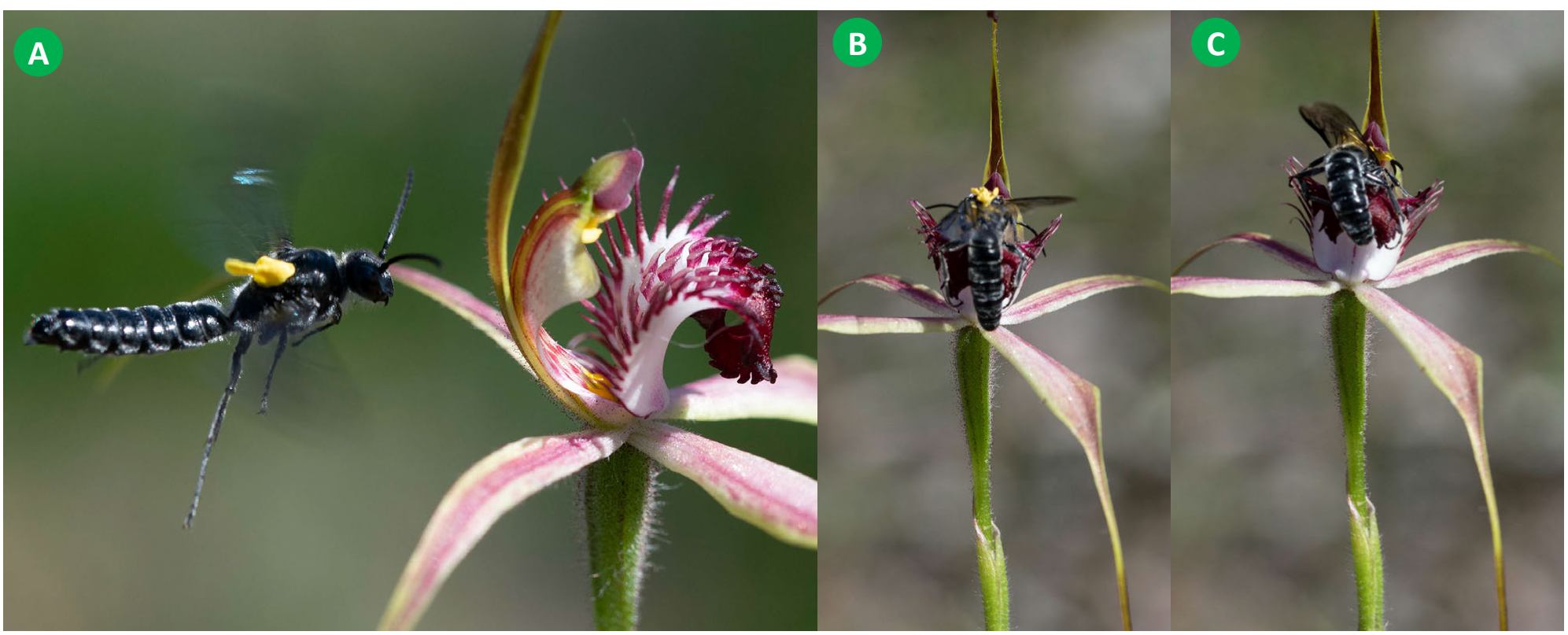




\section{FIgure 5. Queen or Sneba orcnias: Inelymitra varlegata Bunbury (AB), plants hear AIDany (CD) ana I.} speciosa (EF)
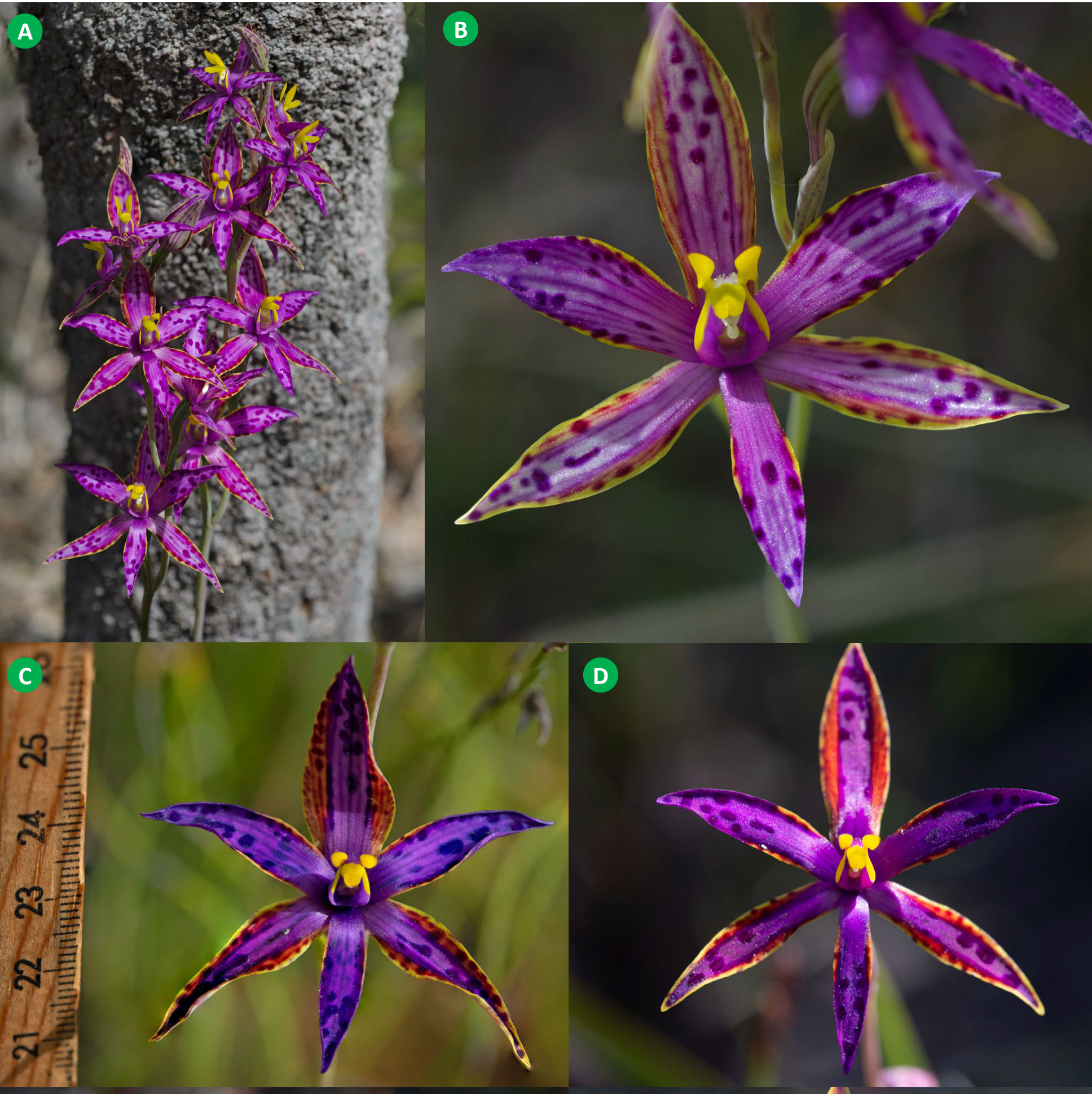

E

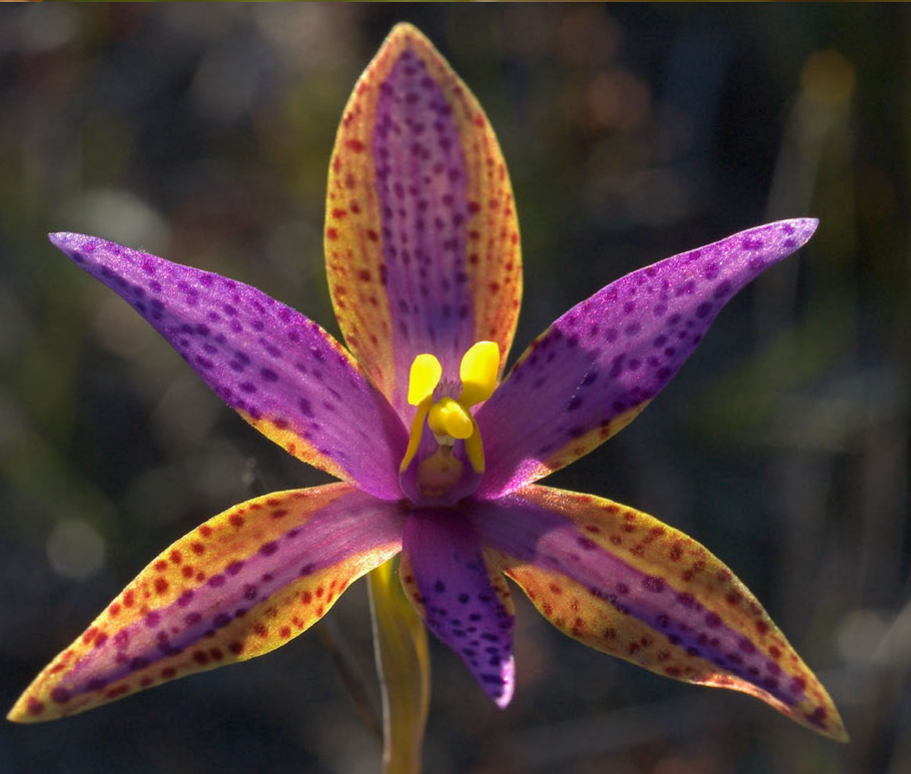

F
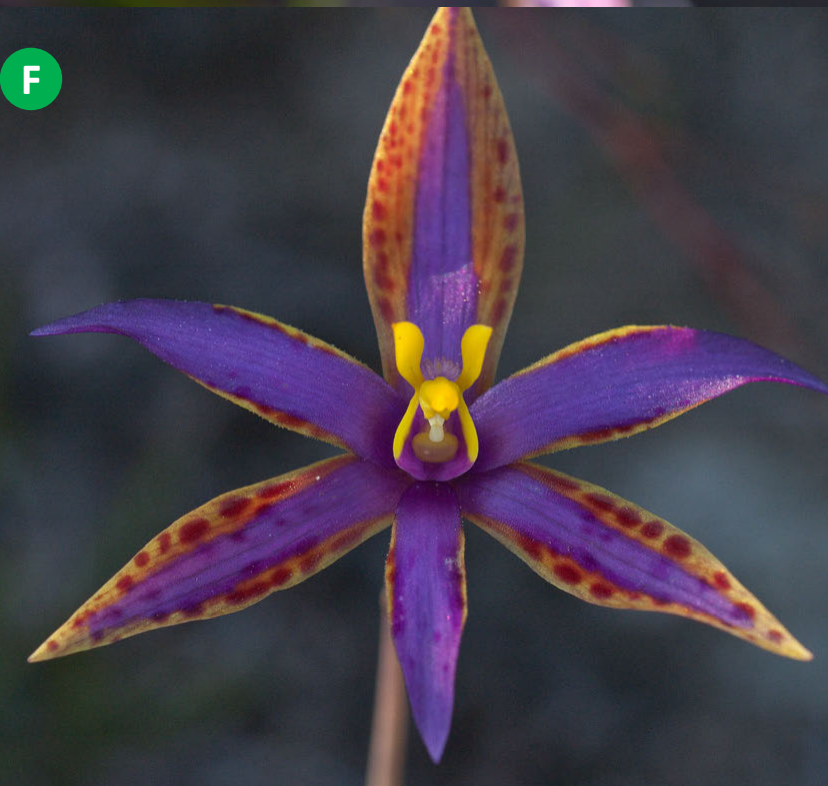
Figure 6. Drakaea elastica cross pollination (A-D) and attaching seed bags (E-F)

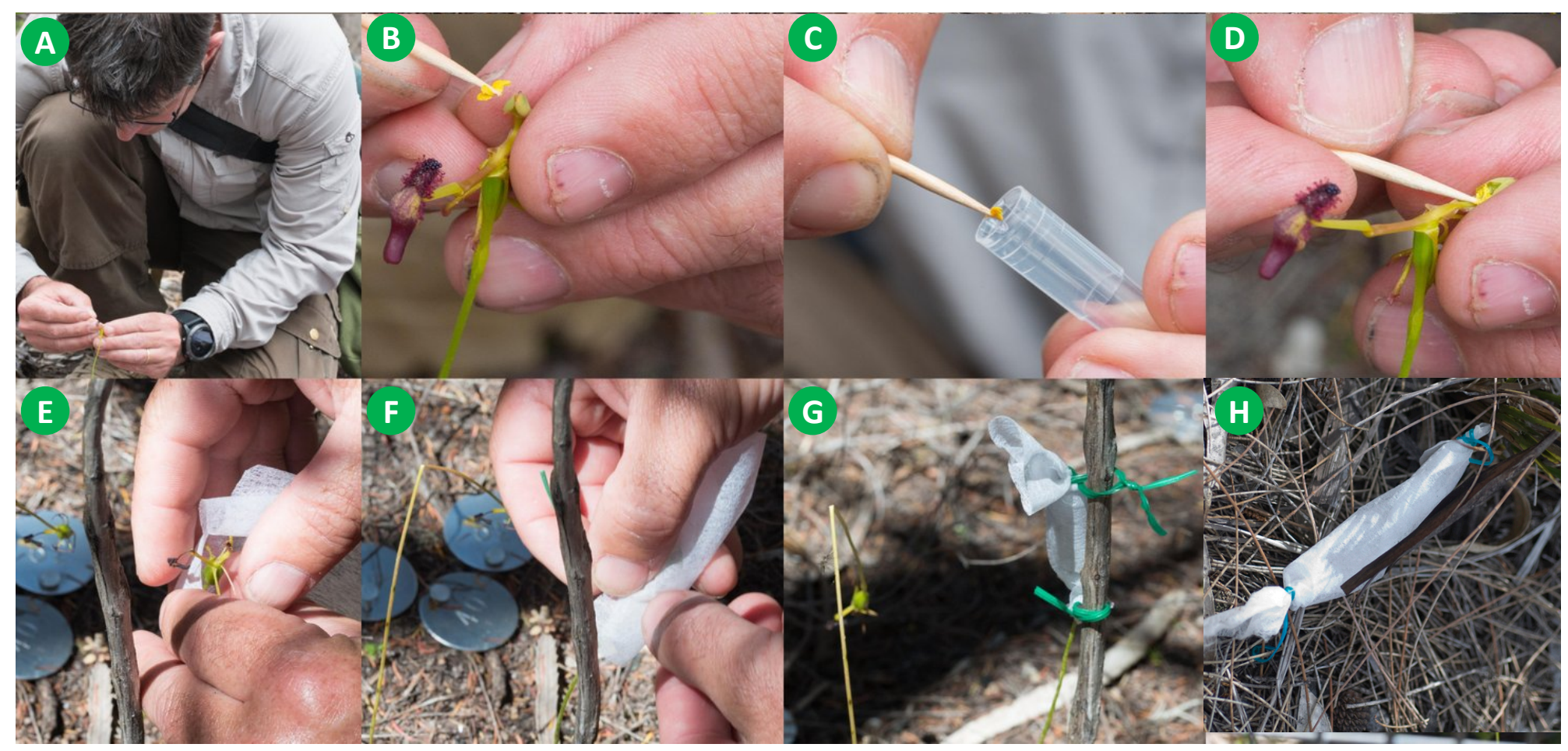

Figure 7. Opening orchid seed bags (A) and seeds viewed und a microscope (BC)

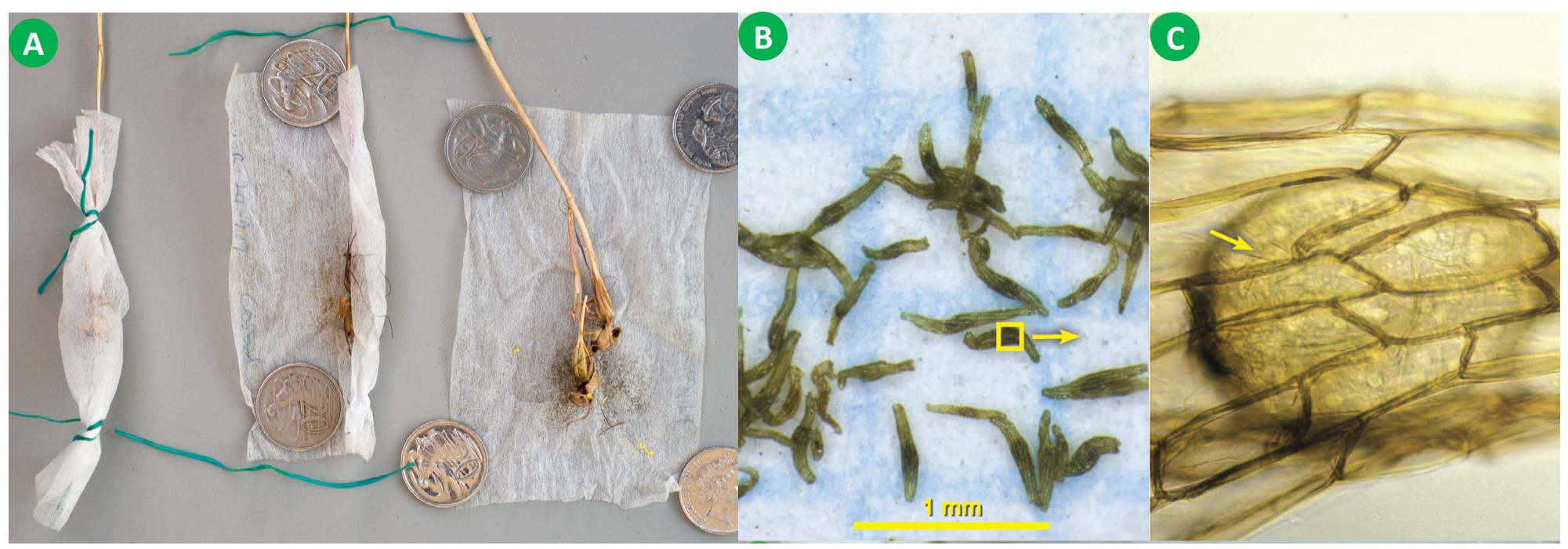

Figure 8. Ex situ orchid seed baiting (A) and protocorms in seed baits (B)
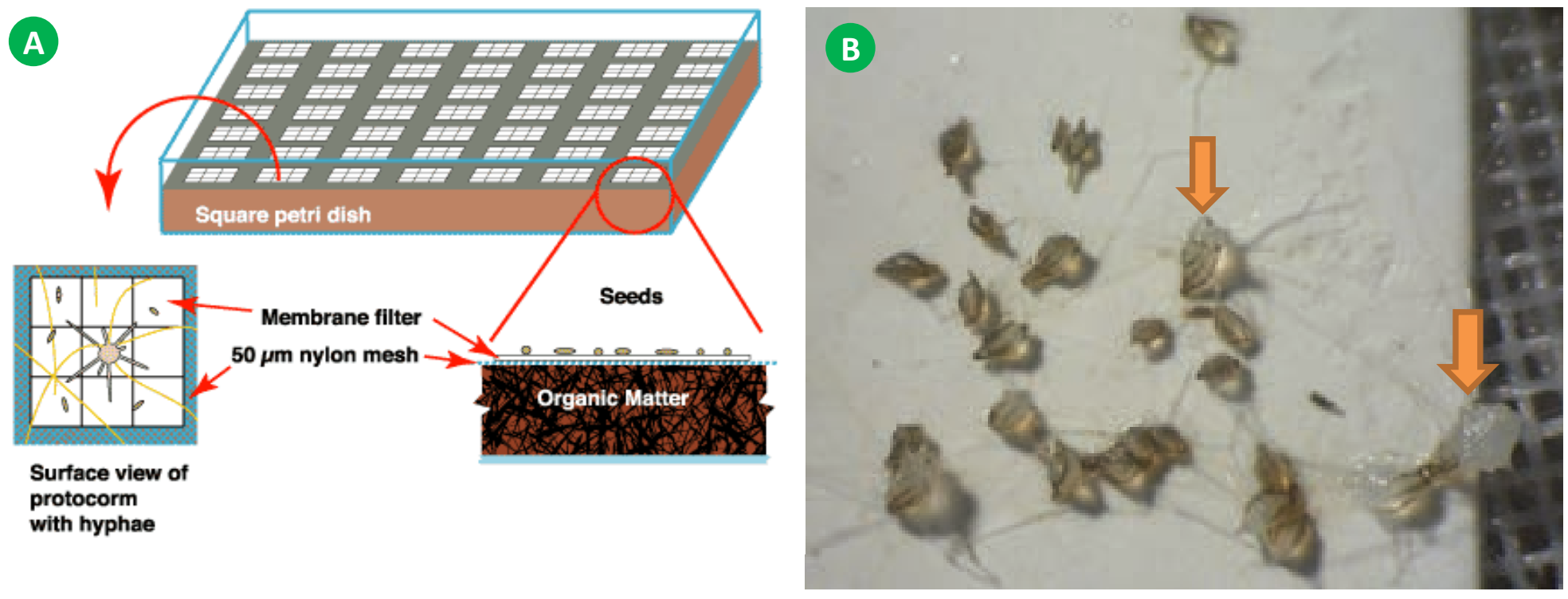


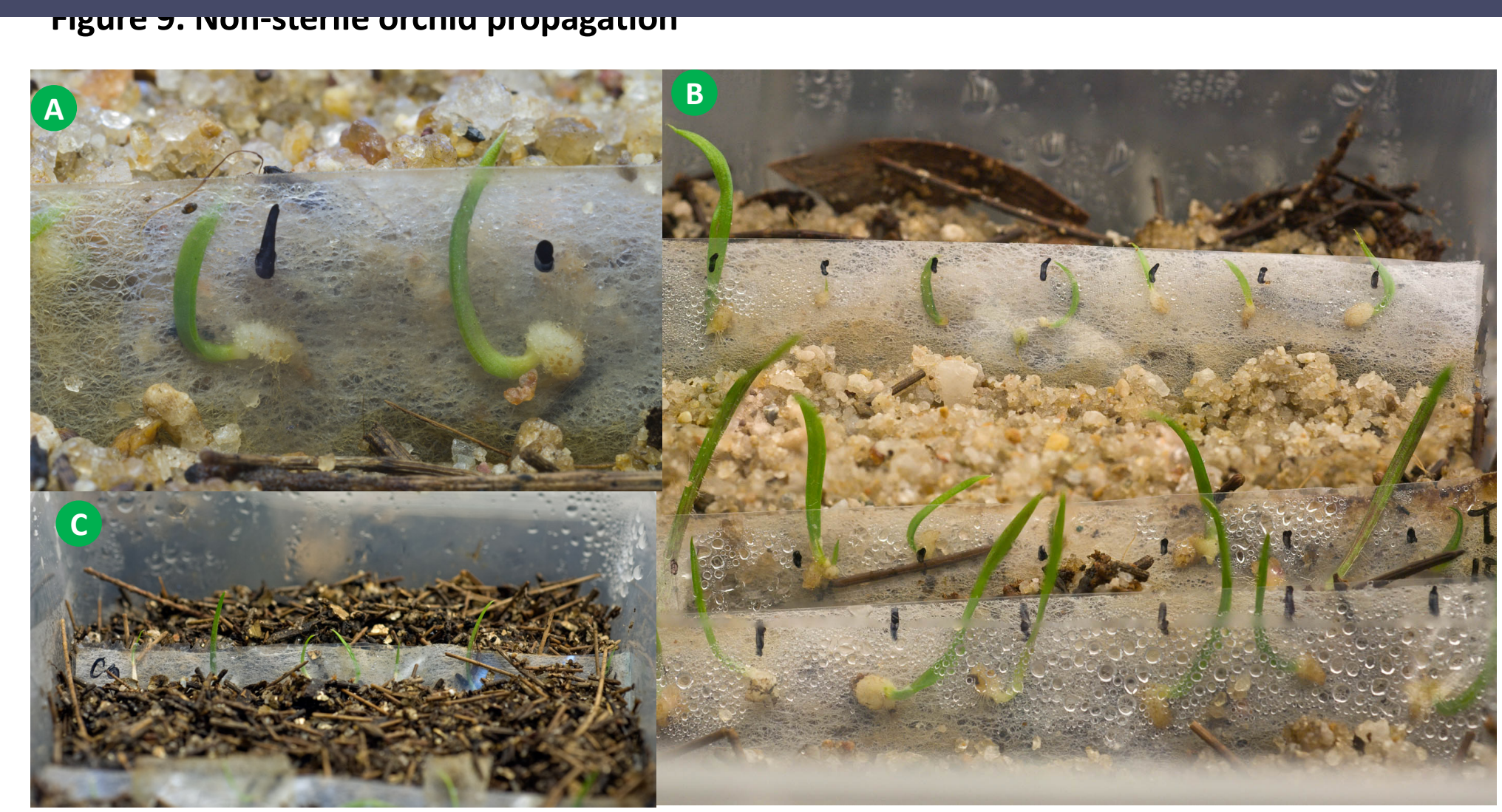

Figure 10. Symbiotic germination with mycorrhizal fungi (A) on agar plates (B)
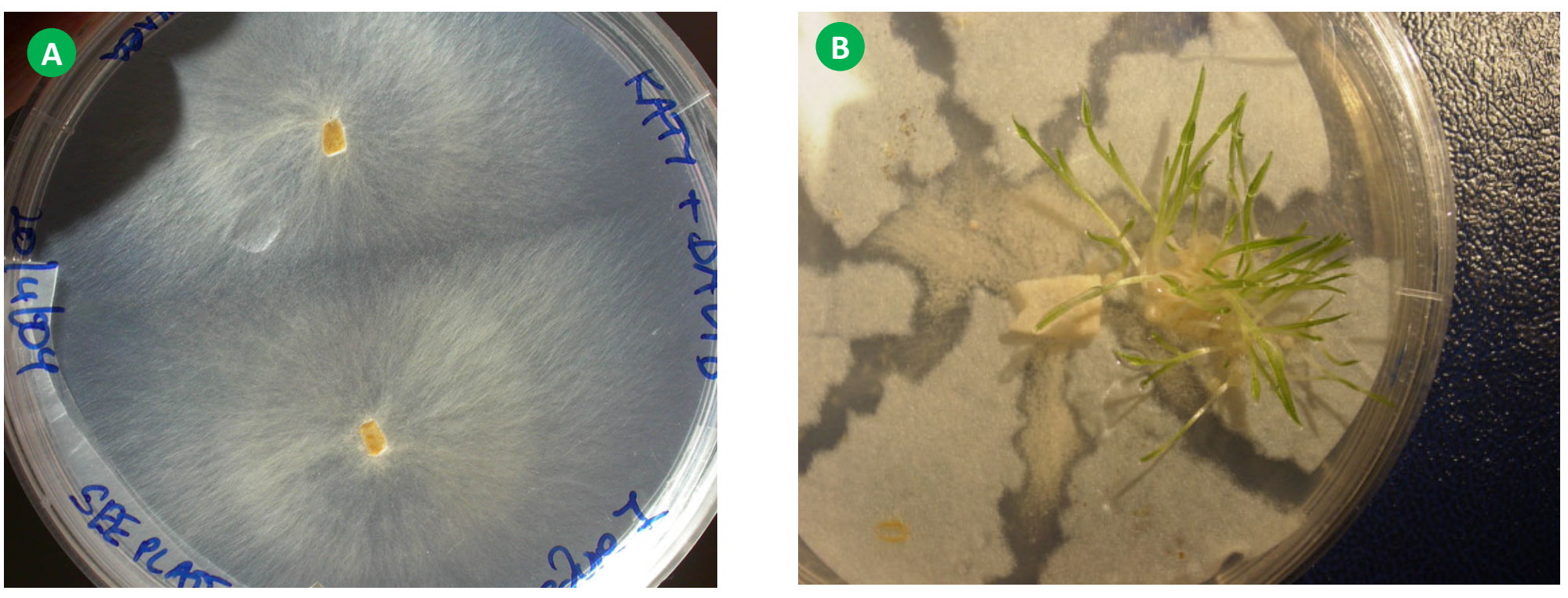

Figure 11. Asymbiotic germination method (A) and seedlings of Caladenia graniticola (B)

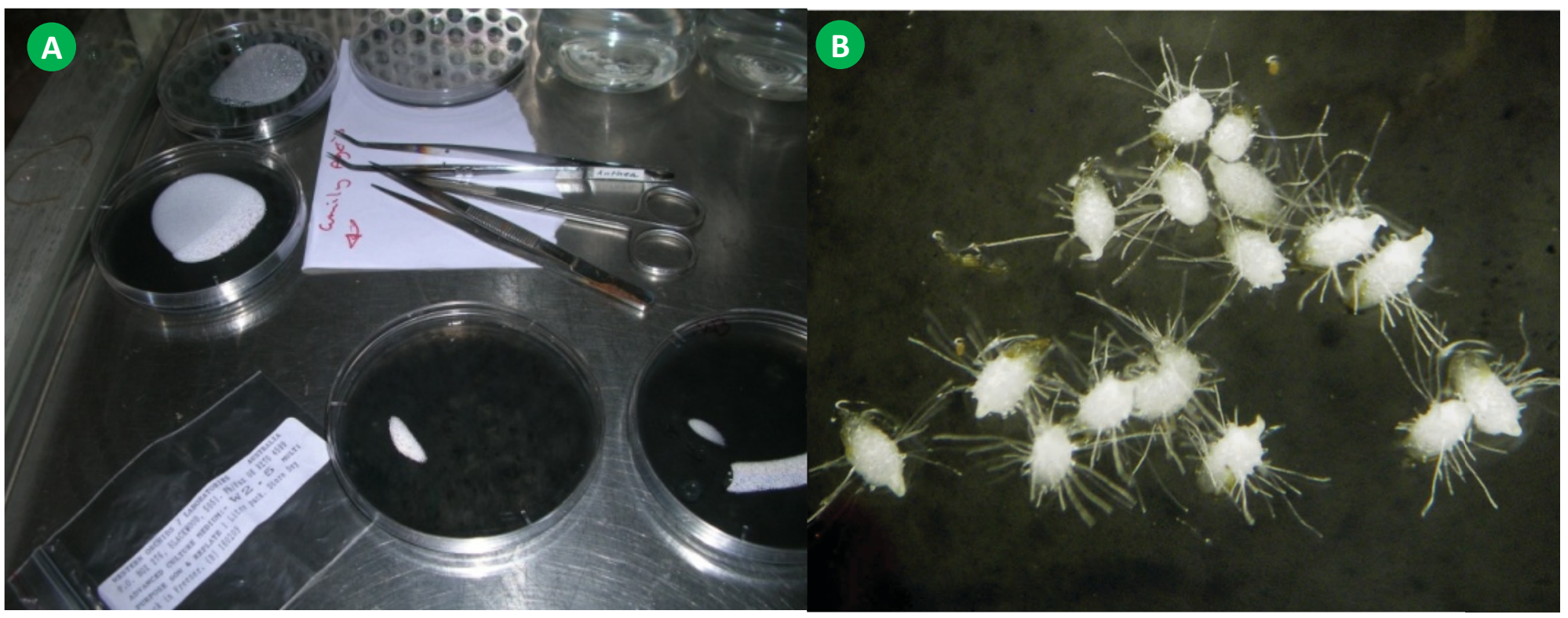


Figure 12. A proposed adaptive management framework for rare orchids

\section{A. Conservation actions}

\section{B. Establishing collaborations and gaining approvals}

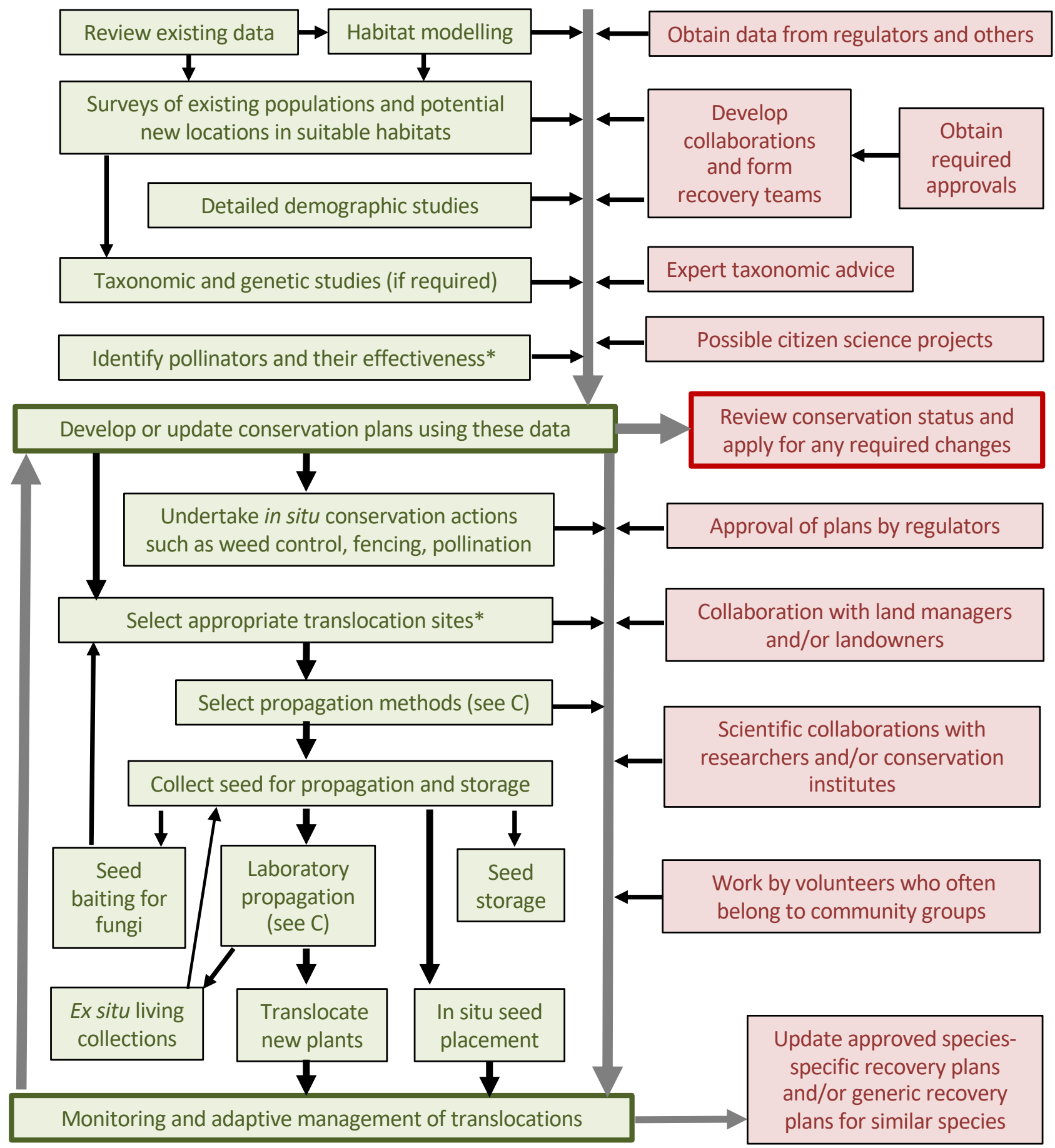

\section{Propagation methods complexity and effectiveness continuum}

In situ seed placement

\begin{tabular}{|c|}
\hline Ex situ \\
seed \\
baiting
\end{tabular}

\begin{tabular}{|l} 
Symbiotic \\
sterile seed \\
germination
\end{tabular}

\section{Asymbiotic} sterile seed germination
Tissue culture

Time taken, cost, complexity of facilities, required training, optimized for some species 